\title{
Posterior Orbitofrontal and Anterior Cingulate Pathways to the Amygdala Target Inhibitory and Excitatory Systems with Opposite Functions
}

\author{
-Basilis Zikopoulos, ${ }^{1,3} \oplus$ Malin Höistad, ${ }^{4} \odot$ Yohan John, ${ }^{2}$ and $\odot H e l e n ~ B a r b a s^{2,3}$ \\ ${ }^{1}$ Human Systems Neuroscience Laboratory, ${ }^{2}$ Neural Systems Laboratory, Department of Health Sciences, and ${ }^{3}$ Graduate Program in Neuroscience, Boston \\ University, Boston, Massachusetts 02215, and ${ }^{4}$ Medical Management Center, Department of Learning, Informatics, Management and Ethics, Karolinska \\ Institute, 17177 Stockholm, Sweden
}

The bidirectional dialogue of the primate posterior orbitofrontal cortex ( $\mathrm{pOFC}$ ) with the amygdala is essential in cognitive- emotional functions. The pOFC also sends a uniquely one-way excitatory pathway to the amygdalar inhibitory intercalated masses (IM), which inhibit the medial part of the central amygdalar nucleus (CeM). Inhibition of IM has the opposite effect, allowing amygdalar activation of autonomic structures and emotional arousal. Using multiple labeling approaches to identify pathways and their postsynaptic sites in the amygdala in rhesus monkeys, we found that the anterior cingulate cortex innervated mostly the basolateral and CeM amygdalar nuclei, poised to activate CeM for autonomic arousal. By contrast, a pathway from pOFC to IM exceeded all other pathways to the amygdala by density and size and proportion of large and efficient terminals. Moreover, whereas pOFC terminals in IM innervated each of the three distinct classes of inhibitory neurons, most targeted neurons expressing dopamine- and cAMP-regulated phosphoprotein (DARPP$32+)$, known to be modulated by dopamine. The predominant POFC innervation of DARPP-32+ neurons suggests activation of IM and inhibition of CeM, resulting in modulated autonomic function. By contrast, inhibition of DARPP-32 neurons in IM by high dopamine levels disinhibits CeM and triggers autonomic arousal. The findings provide a mechanism to help explain how a strong pOFC pathway, which is poised to moderate activity of CeM, through IM, can be undermined by the high level of dopamine during stress, resulting in collapse of potent inhibitory mechanisms in the amygdala and heightened autonomic drive, as seen in chronic anxiety disorders.

Key words: calbindin; DARPP-32; emotions; intercalated masses; macaque brain; nitric oxide synthase

Significance Statement

The dialogue between prefrontal cortex and amygdala allows thoughts and emotions to influence actions. The posterior orbitofrontal cortex sends a powerful pathway that targets a special class of amygdalar intercalated mass (IM) inhibitory neurons, whose wiring may help modulate autonomic function. By contrast, the anterior cingulate cortex innervates other amygdalar parts, activating circuits to help avoid danger. Most IM neurons in primates label for the protein DARPP-32, known to be activated or inhibited based on the level of dopamine. Stress markedly increases dopamine release and inhibits IM neurons, compromises prefrontal control of the amygdala, and sets off a general alarm system as seen in affective disorders, such as chronic anxiety and post-traumatic stress disorder.

\section{Introduction}

Bidirectional connections between the posterior orbitofrontal cortex (pOFC) and the amygdala in primates (Ghashghaei et al., 2007) are associated with evaluating the affective significance of

\footnotetext{
Received Dec. 23, 2016; revised March 10, 2017; accepted March 24, 2017.

Author contributions: B.Z. and H.B. designed research; B.Z. and M.H. performed research; B.Z., M.H., and Y.J. analyzed data; B.Z., M.H., Y.J., and H.B. wrote the paper.

This work was supported by NIH grants from NIMH and NINDS. We thank Drs. Paul Greengard and Jean-Antoine Girault for the gift of the DARPP-32 antibody, Dr. John Fiala for assistance in adapting the free 3D-reconstruction software he developed, Dr. Angela Carville for veterinary care, and Linda Fernsten for surgical assistance.

Correspondence should be addressed to Helen Barbas, Boston University, 635 Commonwealth Avenue, Room 431, Boston, MA 02215. E-mail: barbas@bu.edu.

DOI:10.1523/JNEUROSCI.3940-16.2017

Copyright $\odot 2017$ the authors $\quad 0270-6474 / 17 / 375051-14 \$ 15.00 / 0$
}

events (Salzman et al., 2007; Pessoa, 2010; Salzman and Fusi, 2010; Morrison and Salzman, 2011; Rudebeck et al., 2013). Beyond the bidirectional connections, the pOFC is distinguished for its dense and nonreciprocal pathway to the intercalated masses (IM) of the amygdala (Ghashghaei and Barbas, 2002). The significance of this pathway is based on the entirely inhibitory nature of the IM and its critical role in the internal processing of the amygdala (for review, see Paré et al., 2003; Palomares-Castillo et al., 2012).

The primate IM did not always receive attention commensurate with its key role in the amygdala. Composed of small neurons and squeezed between the amygdala's basal nuclei and below its central (output) nucleus, the IM are dwarfed by the nearby large 
neurons of the basal nuclei. The position of IM in monkeys was traditionally abrogated in most maps of the primate amygdala. Notwithstanding their inconspicuous stature, it is now clear that IM neurons across species have a central role in the amygdala and on downstream influence of autonomic structures (Ghashghaei and Barbas, 2002; Paré et al., 2003).

A recent study revealed an ordered diversity in the GABAergic IM neurons and their intrinsic circuitry in rhesus monkeys (Zikopoulos et al., 2016). By morphology, IM neurons are broadly divided into those with dendritic spines and those without spines. By neurochemistry, IM neurons fall into three classes. The largest class comprises dopamine- and cAMP-regulated phosphoprotein (DARPP-32+) neurons, which are always spiny and include a subset that also expresses calbindin (CB). A second class consists of IM neurons that express CB but are aspiny. A third class includes aspiny neurons that are positive for nitric oxide synthase (NOS) but not CB. This analysis thus segregates the inhibitory neurons in IM into three nonoverlapping classes identified by morphology and neurochemistry (Zikopoulos et al., 2016).

The innervation of the diverse IM inhibitory system by pOFC axons is unknown. In addition, beyond its high density, it is unknown whether the pOFC pathway to IM differs from a lighter pathway that emanates from the anterior cingulate cortex (ACC; area 32) or from either POFC or ACC pathways that variously innervate other nuclei of the amygdala. We addressed these issues from the system to the synapse. We found that the pOFC pathway to IM is robust not only in density but also by the large size of boutons and their proportion, which exceeded all other pathways by pOFC or ACC to other nuclei of the amygdala, or by ACC to IM. Moreover, by a predominant innervation of DARPP-32 neurons in IM, which are differentially engaged based on the level of dopamine in the system, the pOFC pathway is poised to dynamically modulate autonomic drive, a process that goes awry in psychiatric diseases marked by anxiety.

\section{Materials and Methods}

\section{Experimental design}

We injected anterograde neural tracers in $\mathrm{pOFC}$ areas [orbital proisocortex (OPro) and posterior area 13] and in ACC area 32 in rhesus monkeys (Macaca mulatta) to quantitatively examine terminations in the amygdala (Fig. 1). We double and triple immunolabeled coronal sections through the amygdala, to visualize the tracers and several markers of inhibitory neurons. We used three-dimensional (3D) analysis and reconstruction to study close appositions of prefrontal terminals with excitatory and inhibitory structures

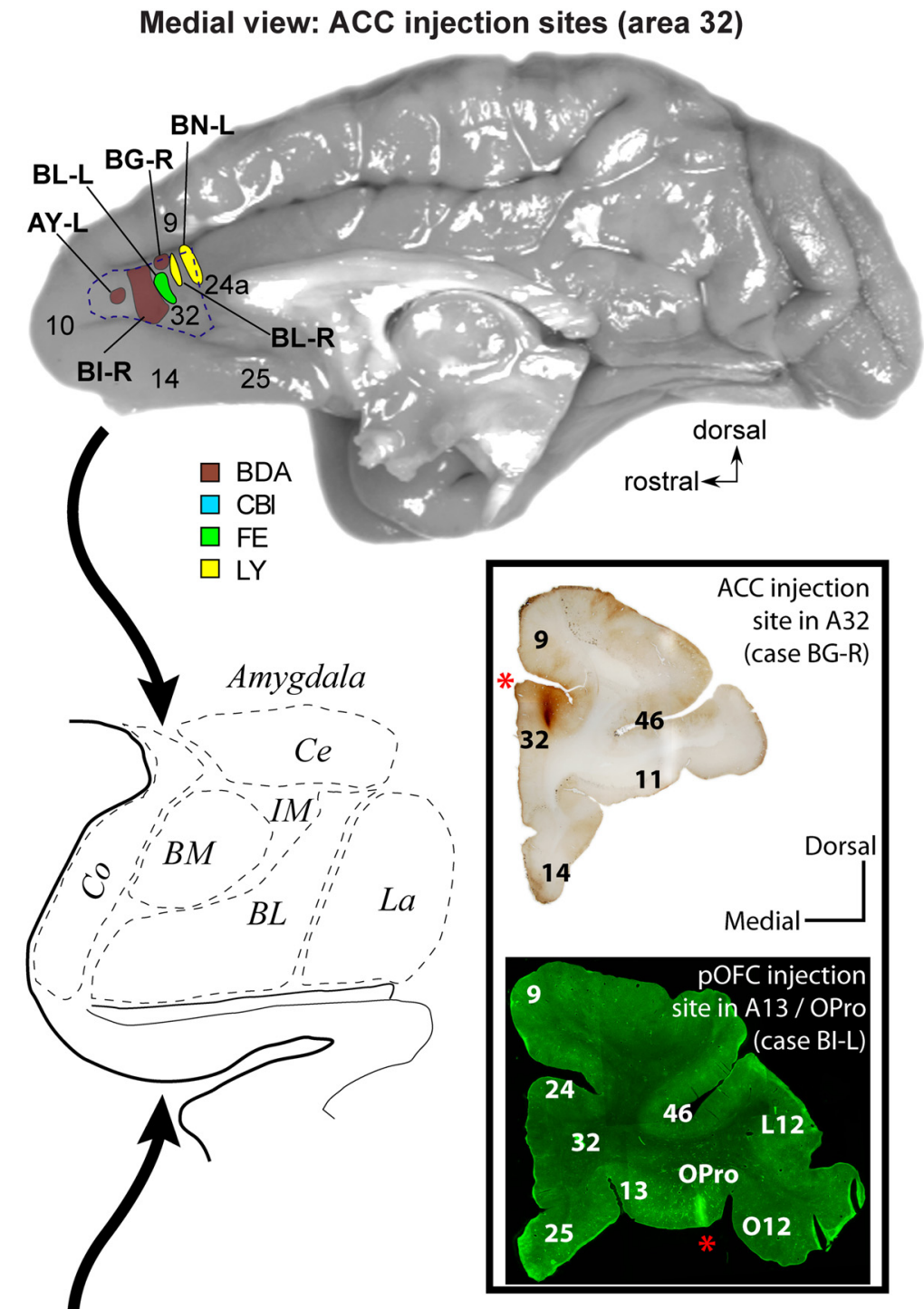

Orbital view: pOFC injection sites (areas 13 and OPro)

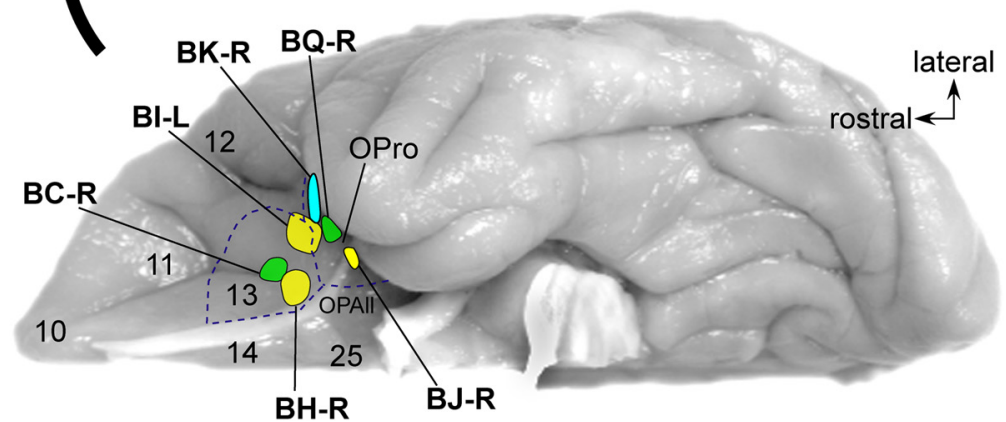

Figure 1. Experimental approach and tracer injections. Anterograde tracers BDA (brown), CBI (blue), FE (green), and LY (yellow) were injected in ACC area 32 (medial view of rhesus macaque brain shown on top) and p0FC (bottom, orbital view of rhesus macaque brain) of 10 animals [left (-L) or right (-R) hemisphere] to study the distribution and overlap of pathways terminating in the amygdala and their interactions with local excitatory and inhibitory neurons. A diagram of a coronal section through the central extent of the amygdala shows key amygdalar nuclei. The inset shows low-magnification images from prefrontal coronal sections with sites injected with neural tracers: BDA in area 32 of case BG-R (brown, top) and LY in area OPro of case BI-L (bottom). Red asterisks indicate injection sites. The BM nucleus is also known as accessory basal. Co, Cortical. Scale bar (inset), $5 \mathrm{~mm}$. at the confocal microscope and serial electron microscopy (EM) to study synaptic features.

Surgery, tracer injections, and tissue processing

Experiments were conducted on 10 adult rhesus monkeys (2-3 years of age; both sexes, $n=7$ female), obtained from the New England Primate 
Research Center (NEPRC), in accordance with the National Institutes of Health Guide for the Care and Use of Laboratory Animals (publication 80-22 revised, 1996). The experiments were approved by the Institutional Animal Care and Use Committee at Boston University School of Medicine, Harvard Medical School, and NEPRC. Procedures were designed to minimize animal suffering and reduce the number of animals needed for research. These cases and injection sites have also been used to study other pathways in previous studies, as described (Barbas et al., 2005; Zikopoulos and Barbas, 2006; Medalla and Barbas, 2009, 2010, 2012; Bunce and Barbas, 2011; Bunce et al., 2013; García-Cabezas and Barbas, 2014; Timbie and Barbas, 2015).

We calculated the stereotaxic coordinates for each tracer injection using the interaural line as reference after obtaining 3D scans of each brain using high-resolution magnetic resonance imaging (MRI) in anesthetized animals, as described (Zikopoulos and Barbas, 2006, 2007b; Medalla and Barbas, 2009; Timbie and Barbas, 2015). One week or longer after the MRI, we injected 3-10 $\mu$ l of $10 \%$ solution of several anterograde tracers in anterior cingulate area 32 (cases AY-L, BG-R, BI-R, BN-L, BL-R, and BL-L) and posterior orbitofrontal areas 13 or OPro (collectively referred to as pOFC; cases BC-R, BH-R, BI-L, BJ-R, BK-R, BN-L, and BQ-R) under general anesthesia. In each case, the tracers were injected in two penetrations (half the quantity in each penetration) at a depth of 1.2-1.6 mm below the pial surface. After injection, the needle was left in place for 10-15 min to allow the dye to penetrate at the injection site and prevent upward suction of the dye during retraction of the needle.

The anterograde tracers we used, namely biotinylated dextran amine (BDA; cases AY-L, BG-R, and BI-R), fluoro-emerald (FE; cases BC-R, BQ-R, and BL-L), cascade blue (CBl; case BK-R), and Lucifer yellow (LY; cases BI-L, BJ-R, BH-R, BL-R, and BN-L; all tracers had a molecular weight of $10 \mathrm{kDa}$; Invitrogen), optimized for anterograde transport to label axons and boutons (Veenman et al., 1992; Reiner et al., 2000). There is, however, minimal transport in the retrograde direction, restricted to labeling of the cell body and proximal dendrites of projection neurons; the tracer does not enter axon collaterals or travel trans-synaptically (Veenman et al., 1992; Richmond et al., 1994; Reiner et al., 2000). The axon boutons seen in the amygdala, therefore, could not have belonged to collateral axons from retrogradely labeled amygdalar neurons or from other areas that project to the prefrontal cortex and the amygdala.

After a survival period of $18-20 \mathrm{~d}$, the animals were anesthetized and transcardially perfused with $4 \%$ paraformaldehyde and $0.2 \%$ glutaraldehyde, and the brains were removed from the skull, cryoprotected in graded solutions of sucrose $(10-30 \%)$, frozen, and cut on a freezing microtome in the coronal plane at $50 \mu \mathrm{m}$ to produce 10 series, as described previously (Zikopoulos and Barbas, 2006, 2007b; Medalla and Barbas, 2009; Timbie and Barbas, 2015). In cases with injection of fluorescent tracers, one series was mounted on glass slides, coverslipped, and used to map labeled neurons and terminals.

\section{Immunohistochemical procedures}

Bright-field and fluorescence microscopy. In experiments with tracer injections, one series of sections was processed to visualize boutons and labeled neurons using standard bright-field or fluorescence immunohistochemical protocols, as described previously (Zikopoulos and Barbas, 2006, 2007b; Medalla and Barbas, 2009; Timbie and Barbas, 2015). Briefly, in cases with

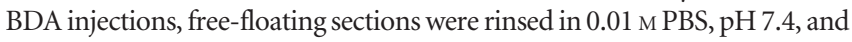
incubated for $1 \mathrm{~h}$ in an avidin-biotin HRP complex (AB-Kit, Vector Laboratories; diluted 1:100 in 0.01 м PBS with $0.1 \%$ Triton X-100). The sections were then washed and processed for immunoperoxidase reaction using diaminobenzidine (DAB; Zymed Laboratories). Sections were then mounted, dried, and coverslipped with Entellan (Merck).

In cases with $\mathrm{FE}, \mathrm{CBl}$, and LY injections in ACC and pOFC, we used polyclonal antibodies (rabbit anti-fluorescein/Oregon Green, RRID: AB_221562; anti-Alexa 405/Cascade Blue, RRID: AB_2314090; and antiLY, RRID: AB_2536190, 1:800; Invitrogen) to convert the fluorescent tracers for viewing under bright-field illumination and visualized label by the peroxidase-catalyzed polymerization of DAB. In cases with fluorescent tracer injections, where we had an additional BDA injection, we incubated sections in AB blocking reagent (Vector Laboratories) or used nonbiotinylated polyclonal anti-rabbit secondary antibody (RRID:
AB_510013) followed by tertiary anti-rabbit solution (PAP method, 1:200, Sternberger Monoclonals; RRID: AB_10119996) to avoid crossreaction with the $\mathrm{BDA}$.

To identify and examine IM inhibitory neurons and their interactions with prefrontal terminals, we performed double or triple immunofluorescence, using antibodies against the inhibitory neurotransmitter GABA, glutamic acid decarboxylase (GAD-67), calcium-binding protein CB, DARPP-32, and NOS/[or histochemical labeling for NADPHdiaphorase, as described previously (Dombrowski and Barbas, 1996; Zikopoulos et al., 2016)]. The tissue was rinsed in 0.01 м PBS, pH 7.4, followed by $10 \%$ normal goat serum, $5 \%$ bovine serum albumin, and $0.1 \%$ Triton X-100 in $0.01 \mathrm{~m}$ PBS blocking solution for $1 \mathrm{~h}$, and incubated overnight in one or two of the following primary antibodies for GABA (1:1000, mouse monoclonal, Sigma, RRID: AB_476667; or 1:1000, rabbit polyclonal, DiaSorin, RRID: AB_572234), GAD-67 (1:200, rabbit polyclonal, Millipore Bioscience Research Reagents, RRID: AB_90715), CB (1:2000, mouse monoclonal, RRID: AB_10000347, or rabbit polyclonal, RRID: AB_10000340, Swant), DARPP-32 (1:30,000, mouse monoclonal; gift from Dr. Paul Greengard, The Rockefeller University, New York, NY, and Dr. Jean-Antoine Girault, INSERM, Sorbonne Universites, Paris, France), and bNOS (1:250, mouse monoclonal or rabbit polyclonal, $\mathrm{b}$ isoform (neuronal) NOS, Transduction Laboratories, RRID: AB_2314961). The sections were rinsed in PBS, incubated for $1 \mathrm{~h}$ with a goat anti-rabbit (for polyclonal) or anti-mouse (for monoclonal) IgG conjugated with the fluorescent probes Alexa Fluor 488 (green) or Alexa Fluor 568 (red) or Alexa Fluor 405 (blue; 1:100, Invitrogen; RRIDs: AB_2556548, AB_2534072, AB_221604, AB_221605, AB_2534123, and AB_2576217) and thoroughly rinsed with PBS. In some cases, a biotinylated secondary antibody and an avidin-biotin-peroxidase kit was used to label inhibitory neurons with DAB. To exclude any nonspecific immunoreactivity, we performed control experiments, with sections adjacent to those used in the experiments described above. These included omission of the primary antibodies and incubation with all secondary or tertiary antisera used. All control experiments resulted in no immunohistochemical labeling.

Electron microscopy. Sections treated for bright-field BDA, FE, CBl, or LY were processed for electron microscopy (cases BI-R, BJ-R, BK-R, $\mathrm{BN}-\mathrm{L}$, and $\mathrm{BQ}-\mathrm{R})$. We used the protocols described above, but Triton $\mathrm{X}-100$ concentration in all solutions was reduced to $0.025 \%$. To determine the postsynaptic targets of labeled axon terminals from prefrontal areas in the amygdala, we double and triple labeled sections using antibodies against GABA and/or CB and pre-embedding immunohistochemistry. Prefrontal terminals labeled with tracers were visualized with $\mathrm{DAB}$ as described previously, and sections were incubated in avidin-biotin blocking kit solutions (Vector Laboratories) to block free binding sites. Inhibitory GABAergic neurons were visualized with gold-conjugated antirabbit or anti-mouse secondary antibodies (1:50; gold particle diameter, 1 nm; GE Healthcare, RRID: AB_1062550 for anti-mouse, RRID: AB_1062553 for anti-rabbit), as described previously (Zikopoulos and Barbas, 2006, 2007b; Zikopoulos et al., 2016). Sections were also coincubated overnight with $\mathrm{CB}$ (as above) and processed for immunoperoxidase reaction using tetramethylbenzidine (TMB; $5-15$ min incubation; $0.005 \%$ TMB in $100 \%$ ethanol, $5 \%$ ammonium paratungstate, $0.004 \% \mathrm{NH}_{4} \mathrm{Cl}$, and $0.005 \%$ $\mathrm{H}_{2} \mathrm{O}_{2}$ in $0.1 \mathrm{M} \mathrm{PB}, \mathrm{pH}$ 6), which produces a reaction product of grainy rods that is distinct from the uniform reaction product of DAB. To prevent diffusion of the gold particles, tissue was postfixed in a microwave with $6 \%$ glutaraldehyde after quick rinses in PBS. Gold labeling was intensified with the use of a silver enhancement kit (IntenSE, GE Healthcare).

Tissue sections with label were mounted on slides and quickly viewed under the light microscope, and images were captured with a CCD camera. Small blocks of sections with anterograde, GABA, and CB label were cut under a dissecting microscope, postfixed in $1 \%$ osmium tetroxide with $1.5 \%$ potassium ferrocyanide in phosphate buffer $(\mathrm{PB})$, washed in buffer (PB) and water, and dehydrated in an ascending series of alcohols. While in $70 \%$ alcohol, they were stained with $1 \%$ uranyl acetate for 30 min. Subsequently, they were cleared in propylene oxide and embedded in Araldite at $60^{\circ} \mathrm{C}$. Serial ultrathin sections $(50 \mathrm{~nm})$ were cut with a diamond knife (Diatome) using an ultramicrotome (Ultracut, Leica) and collected on single slot grids to view with a transmission electron microscope (100CX, JEOL). 


\section{Stereological analysis and $3 D$ reconstruction}

Light and confocal laser microscopy. We delineated prefrontal cortical areas and the nuclei of the amygdala from Nissl- and acetylcholinesterase-stained sections matched to sections that were immunohistochemically labeled. The nomenclature we used for the amygdala was according to the maps used previously (Ghashghaei and Barbas, 2002; Zikopoulos et al., 2016), based on classic maps (Johnston, 1923; Price et al., 1987; De Olmos, 1990).

We viewed immunolabeled sections under bright-field or fluorescence/confocal laser illumination and outlined brain sections, placed architectonic borders of amygdalar nuclei, and mapped labeled pathways in each case with the aid of a commercial computerized microscope system and motorized stage (Neurolucida, MicroBrightField, RRID: SCR_001775). The procedure involves setting a reference point for every brain hemisphere analyzed, and as a result, the outlines are automatically registered and aligned to the actual corresponding sections, retaining information about the 3D coordinates of every mark or trace. We used these sections and outlines for stereological analyses and to compare the relative topography and distribution of anterograde labeling across cases and injection sites.

Images presented or used for analyses were captured at high resolution with a CCD camera (DP-70), mounted on an Olympus Optical BX51 microscope, and connected to a personal computer, using commercial imaging systems [MetaMorph version 4.1 (Universal Imaging Corporation, RRID:SCR_002368) or Neurolucida]. For confocal images, we used an Olympus Fluoview or a Zeiss LSM 510 microscope and viewed sections under high magnification $(1000 \times)$. We acquired image stacks of several focal planes in each area of interest resulting in pictures with high depth of field of 50- $\mu \mathrm{m}$-thick sections focused throughout the extent of their $z$-axes. We applied 3D-deconvolution algorithms to images before analysis with the aid of Autodeblur (Media Cybernetics, RRID: SCR_002465). Stacks were reconstructed in 3D and rotated (in $1^{\circ}$ increments in the $x$-, $y$-, or $z$-axis) using the ImageJ (RRID: SCR_003070) "3D-project" plug-in to visualize close appositions between labeled axon terminals from ACC or pOFC and GABA+, GAD-67+, $\mathrm{CB}+, \mathrm{NOS}+$, or DARPP-32+ inhibitory IM neurons.

Bouton population analysis and density. We analyzed anterograde labeling in the amygdala at high magnification $(1000 \times)$ using unbiased stereological methods (Howard and Reed, 1998), as described previously (Zikopoulos and Barbas, 2006, 2012). Briefly, the systematic, random sampling fraction was $1 / 50$ of the total volume of the region studied and resulted in measuring the morphological characteristics of $>2000$ labeled bouton profiles in each case. The morphological characteristics measured were the minor and major diameter, perimeter, and surface area.

We plotted and estimated the numbers of anterogradely labeled boutons from axons of neurons originating in prefrontal cortex and terminating in the amygdala, using either exhaustive sampling of selected sections or the unbiased stereological method of the optical fractionator (Gundersen, 1986; Howard and Reed, 1998) with the use of specific software (Neurolucida and StereoInvestigator, MicroBrightField, RRID: SCR_002526), as described previously (Zikopoulos and Barbas, 2006, 2012). The advantage of the optical fractionator is that it is not affected by tissue shrinkage (Gundersen, 1986; West et al., 1991; Howard and Reed, 1998). Using the StereoInvestigator software, we measured the height of each section before counting the particles of interest. To ensure an unbiased estimate of objects counted, the method uses a guard zone at the bottom and top of each section to correct for objects plucked during sectioning, so the disector thickness is always smaller than the thickness of the section.

The sampling fraction was $1 / 20$ of the total volume of each nucleus examined for bouton number estimation and was determined in pilot studies using exhaustive sampling of a complete series and progressive means analysis so that final estimates had a coefficient of error $\leq 10 \%$. The use of uniform random sampling ensured that every part of each nucleus examined had the same chance of being included in the sample. Large and small boutons were measured separately and were systematically distinguished based on the results of the bouton population analyses (see previous section). The estimated numbers of boutons and the volumes of the corresponding nuclei estimated with the Cavalieri method were divided to assess the density of label in each case. We normalized data by expressing the number or density of large and small boutons as a percentage of the total number or maximum density of all labeled boutons in the amygdalar nuclei in each case.

Electron microscopy. We viewed $>200$ labeled boutons emanating from prefrontal axons from ACC and pOFC, as well as neighboring unlabeled boutons forming synapses in the IM and the basolateral (BL) nuclei of the amygdala at high magnification $(10,000 \times$ to $30,000 \times)$. We captured high-resolution images with a digital camera (ES1000W, Ga$\tan$ ) attached to the electron microscope (JEOL). We estimated the major and minor diameters of most boutons from miniseries of $\sim 10$ images (2D analysis) and used the average radius $(r)$ of each bouton to estimate corresponding volumes, assuming spherical shape (volume, $4 / 3 \pi \mathrm{r}^{3}$ ). We photographed $\sim 50$ boutons throughout their entire extent (between 10 and 80 serial ultrathin sections) using exhaustive sampling and imported them as a series in Reconstruct (Fiala, 2005) and aligned them. We then traced boutons, postsynaptic densities, and postsynaptic structures (e.g., dendrites). We calibrated section thickness through measurements of the diameter of mitochondria as described previously (Zikopoulos and Barbas, 2006). We reconstructed structures in $3 \mathrm{D}$ and calculated their volumes, surface areas, and diameters. We used all estimated volumes and diameters from the 2D and 3D EM analyses for regressions and correlations. We used classic criteria for identifying synapses and profiles as described previously (Peters et al., 1991; Zikopoulos and Barbas, 2006). Photomicrographs were prepared with Adobe Photoshop (RRID: SCR_014199) and Illustrator (RRID: SCR_014198; Adobe Systems), and overall brightness and contrast were adjusted without retouching.

\section{Statistical analysis}

Data were evaluated with Statistica (StatSoft; RRID: SCR_014213), through scatter and frequency distribution plots and K-means cluster analysis with parameters set to maximize initial between-cluster distances. We used $\chi^{2}$ and Kolmogorov-Smirnov tests to examine bouton size distributions. We used ANOVA to test for differences among bouton populations and densities, and $p$ values $<0.01$ were taken as statistically significant. Post hoc analysis using Bonferroni's/Dunn's (all means) test was performed to identify possible differences between groups (cases with ACC or pOFC injection sites).

\section{Results}

The injection sites encompassed several sites of ACC (area 32) and pOFC (areas 13 and OPro) but were restricted within the respective areas (Fig. 1). In all cases, the injection sites covered all layers, with the exception of a small injection site in area 13 (case BC-R), which was restricted to the deep layers (5-6), the main layers that give rise to projections to the amygdala. These cases and injection sites will be described briefly here, as they were previously used to study other connections of ACC and pOFC (Barbas et al., 2005; Zikopoulos and Barbas, 2006; Medalla and Barbas, 2009, 2010, 2012; Bunce and Barbas, 2011; Bunce et al., 2013; García-Cabezas and Barbas, 2014; Timbie and Barbas, 2015). Tracer injections in ACC included two small injections in anterior area 32 (case AY-L) and dorsal/posterior area 32, near the border with area 9 (case BG-R), as well as larger injections in central (case BI-R) and posterior (cases BN-L, BL-R, and BL-L) area 32. Tracer injections in the pOFC included small injections in area 13 (cases BC-R and BH-R) and lateral (case BK-R), central (cases BI-L and BQ-R), and medial (case BJ-R) parts of area OPro.

\section{Differential distribution of pOFC and ACC projections to the amygdala}

As shown in Figure 2, axons from pOFC and ACC terminated in several nuclei of the amygdala. Both prefrontal regions heavily targeted the BL nucleus of the amygdala. Moderate to low axon terminations were found in the basomedial (BM) nucleus (also 
A Anterior

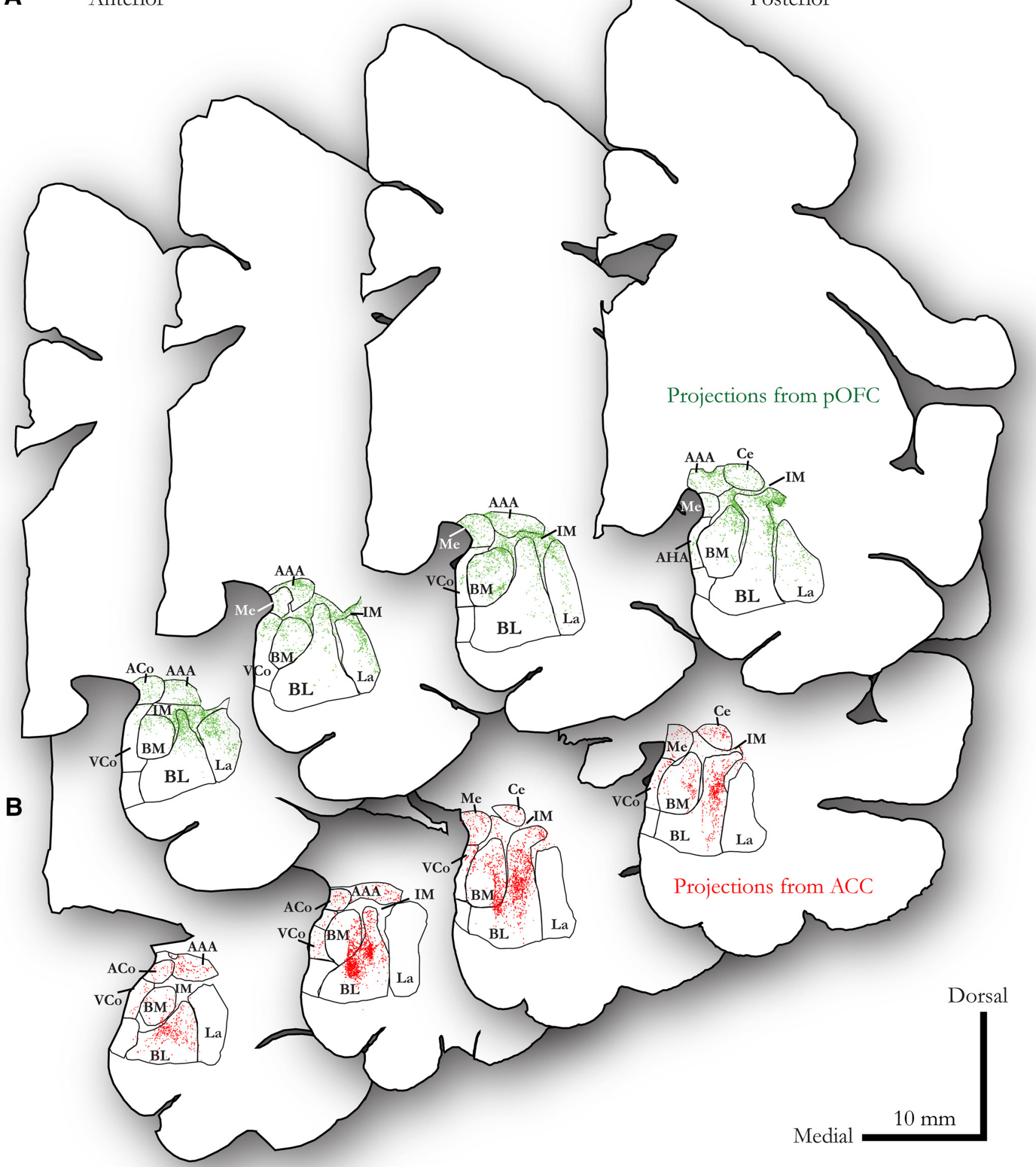

Figure 2. Differential distribution of axon terminations from POFC and ACC in the amygdala. Outlines of series of representative coronal sections from a reference case for each injection site show labeled boutons from different tracer injections superimposed by their relative stereotaxic coordinates. Pathways from pOFC (top, green dots) and ACC (bottom, red dots) terminated widely throughout the anteroposterior and mediolateral extent of the amygdala, but pOFC strongly targeted the IM whereas ACC targeted mostly the BL nucleus. Each dot represents one axon terminal. $\mathrm{AAA}$, Anterior amygdalar area; $\mathrm{AC}$, anterior subdivision of the cortical nuclei; $\mathrm{VC} 0$, ventral subdivision of the cortical nuclei. 


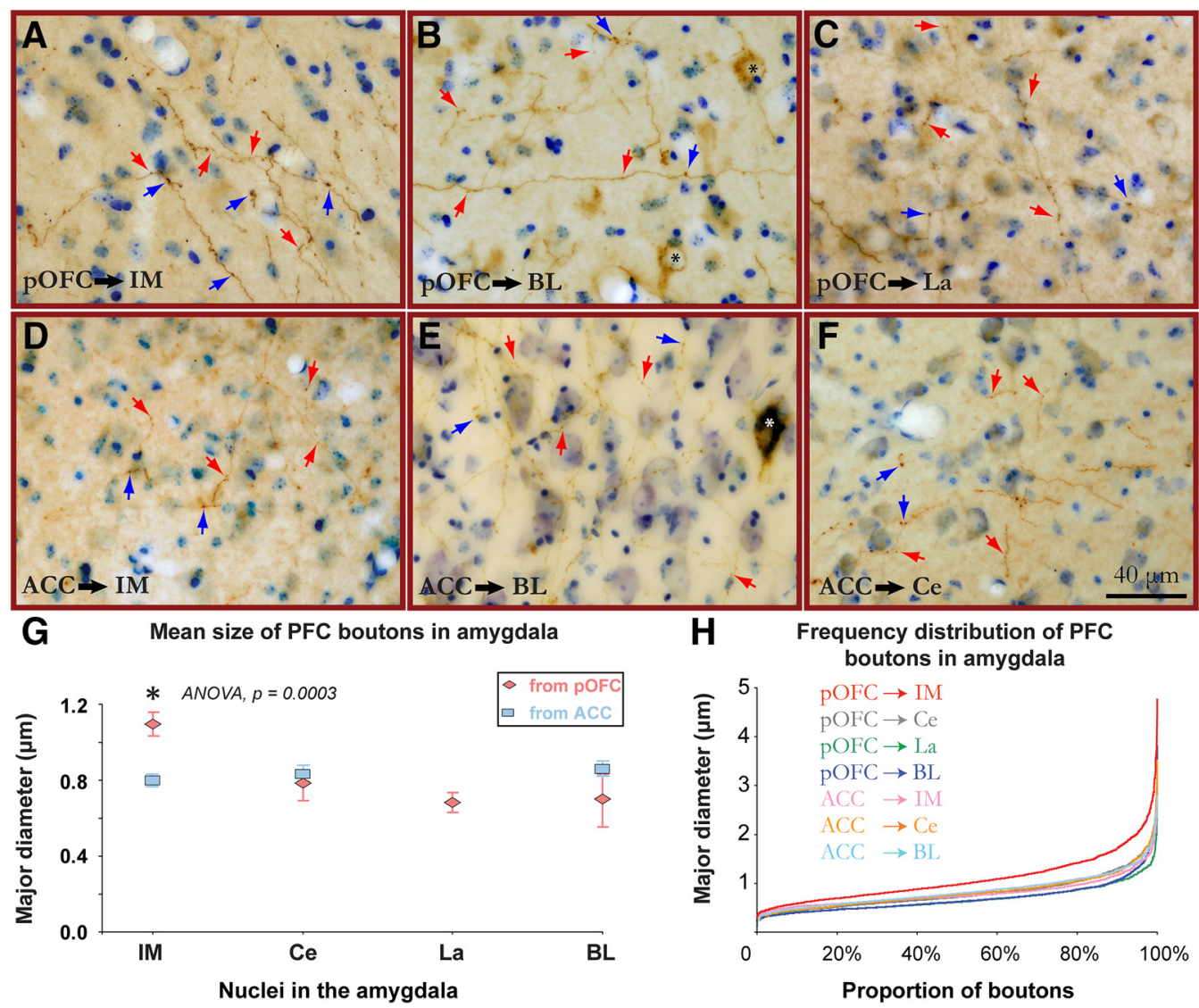

Figure 3. Labeled pathways from pOFC and ACC terminated with large and small boutons in the amygdala. $A-C$, BDA-labeled fibers from pOFC to IM $(\boldsymbol{A})$, BL nucleus $(\boldsymbol{B})$, and La nucleus $(\boldsymbol{C})$ with large (blue arrows) and small (red arrows) boutons. D-F, BDA-labeled fibers from ACC to IM (D), BL nucleus ( $\boldsymbol{E}$ ), and Ce nucleus $(\boldsymbol{F})$ with large (blue arrows) and small (red arrows) boutons. Three projection neurons with labeled somata and proximal dendrites are visible in $\boldsymbol{B}$ and $\boldsymbol{E}$ (asterisks). $\boldsymbol{G}$, Comparison of bouton populations from pOFC and ACC in amygdalar nuclei showed that boutons from $\mathrm{POFC}$ to IM were significantly larger than all other terminations from $\mathrm{POFC}$ and ACC in the amygdala. Asterisk indicates statistically significant difference. $\boldsymbol{H}$, Size distribution frequency of labeled boutons in amygdalar nuclei from axons originating in POFC and ACC. The frequency for the population of terminations from pOFC to IM (red line) was skewed upward, indicating overall more large terminals.

known as accessory basal); anterior amygdalar area; anterior, posterior, and ventral subdivisions of the cortical nuclei; and the medial nucleus. These findings confirm and extend previous data (Ghashghaei and Barbas, 2002; Stefanacci and Amaral, 2002).

Quantitative comparison of axon terminations from pOFC and ACC showed a differential distribution of terminals within amygdalar nuclei (Figs. $3 A-F, 4 B$ ). The most robust terminations from ACC area 32 ( $n=3$ cases) in the amygdala were in $\mathrm{BL}$ nucleus (69\% of all ACC terminations), whereas $28 \%$ of all pOFC ( $n=3$ cases) terminations were found in BL nucleus (Fig. $4 B$ ). The ACC had robust terminations in the central (Ce) nucleus ( $12 \%$ of all terminations; Fig. $4 B$ ), especially in its medial sector, which is the main subcortical output of the amygdala (Price and Amaral, 1981), whereas pOFC projections to Ce were sparser (5\% of all terminations; Fig. 4B). On the other hand, only the pOFC pathway terminated in the sensory-related lateral (La) nucleus ( $20 \%$ of all terminations; Fig. $4 B$ ), with anterograde label found mostly in the dorsal (upper) parts of the nucleus. Labeled axons from pOFC densely terminated in the inhibitory IM $30 \%$ of all terminations; Fig. 4B), which contain small/medium-sized GABAergic neurons interposed between the BM, BL, Ce, and $\mathrm{La}$ nuclei of the amygdala. The pOFC terminations in IM were among the densest projections within the amygdala, confirming and extending previous findings (Ghashghaei and Barbas, 2002). Compared with pOFC, ACC (area 32) projections to IM were sparse ( $8 \%$ of all terminations; Fig. $4 B$ ).
The above descriptions on the density of label were corroborated using an unbiased stereologic method to estimate axon bouton density based on the volume of each nucleus (Howard and Reed, 1998). This analysis revealed that the densest terminations from pOFC were in the pathway to IM $(114,917 \pm 36,416$ boutons $/ \mathrm{mm}^{3}$ ), which received 2.4 times denser terminations than the overall terminations in the amygdala $(47,388 \pm 25,362$ boutons $/ \mathrm{mm}^{3}$ ), followed by the pathway to BM nucleus $\left(102,288 \pm 31,515\right.$ boutons $\left./ \mathrm{mm}^{3}\right)$, then to BL $(61,542 \pm 32,724$ boutons $\left./ \mathrm{mm}^{3}\right)$, La $\left(61,370 \pm 38,925\right.$ boutons $\left./ \mathrm{mm}^{3}\right)$, and Ce $\left(36,867 \pm 14,024\right.$ boutons $\left./ \mathrm{mm}^{3}\right)$ nuclei. The same analysis for the ACC area 32 pathway showed that the densest terminations were in BL nucleus $\left(139,042 \pm 43,722\right.$ boutons $\left./ \mathrm{mm}^{3}\right)$, which received 3.2 times denser terminations than the overall terminations in the amygdala from area $32(43,241 \pm 11,499$ boutons/ $\left.\mathrm{mm}^{3}\right)$, followed by the pathway to Ce nucleus $(98,875 \pm 32,412$ boutons $\left./ \mathrm{mm}^{3}\right)$, then to IM $\left(38,824 \pm 15,361\right.$ boutons $\left./ \mathrm{mm}^{3}\right)$ and BM nucleus $\left(23,975 \pm 15,861\right.$ boutons $\left./ \mathrm{mm}^{3}\right)$; there was no evidence of signal in La nucleus.

\section{Dual mode of prefrontal terminations in the amygdala}

We next investigated the size of labeled terminals at the population level, using stereological sampling methods at the light microscope ( $1000 \times$ magnification; $>2000$ boutons per case). This analysis is based on evidence that large boutons have more mitochondria and more synaptic vesicles than small boutons, in pro- 


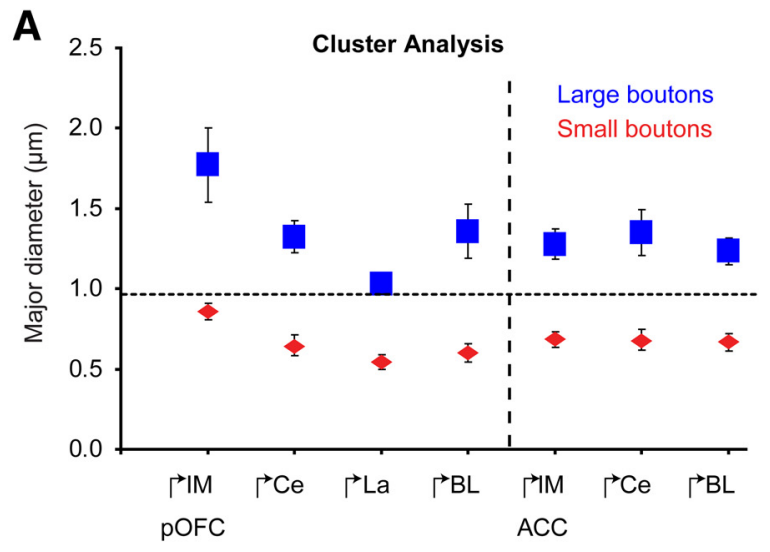

B

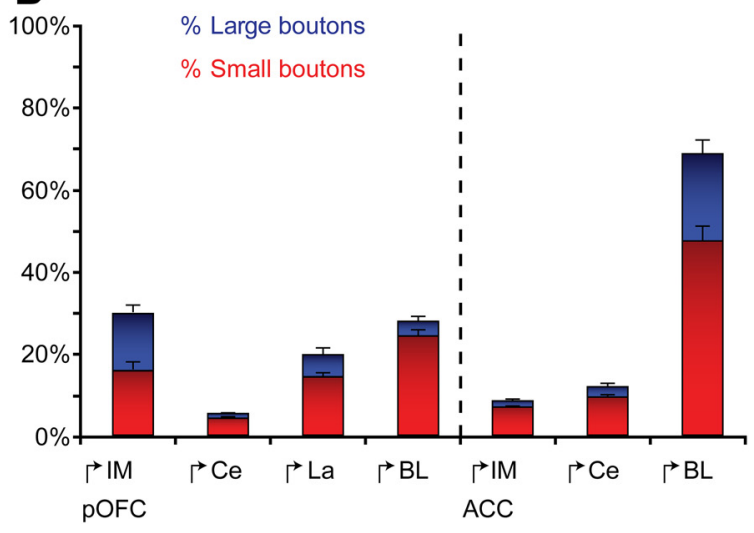

Figure 4. Differences in the size and relative density of axon terminations from p0FC and ACC in amygdalar nuclei, based on bright-field and confocal microscopy. $\boldsymbol{A}$, Cluster analysis and subsequent comparison of bouton populations from pOFC and ACC in amygdalar nuclei showed that there were distinct populations of large and small boutons. Boutons from pOFC in IM were larger than all other boutons in their respective size groups. $\boldsymbol{B}$, Proportion of large and small boutons in each pathway shows a higher relative proportion of large boutons from pOFC to IM $(\sim 1: 1)$, compared with other pathways, suggesting that this is a robust connection. The plot also highlights the relative prevalence of axon terminals from pOFC and ACC in different amygdalar nuclei, with pOFC targeting mostly the IM, followed by BL, La and Ce nuclei, whereas ACC overwhelmingly targeted the BL nucleus, followed by Ce nucleus and IM.

portion to their size (Pierce and Mendell, 1993; Pierce and Lewin, 1994; Shepherd and Harris, 1998; Germuska et al., 2006; Zikopoulos and Barbas, 2007b). We found that pOFC terminals in IM were significantly larger than other terminals in the amygdala from either pOFC or ACC (Fig. 3). The major diameter of labeled boutons in IM originating from pOFC was $\sim 30 \%$ larger than pOFC boutons in Ce, La, or BL nuclei. The pOFC boutons in IM were also significantly larger than boutons from area 32 in IM. In contrast, the terminations from pOFC and ACC were comparable in other nuclei of the amygdala (Ce, La, and BL; Fig. $3 G$ ). Interestingly, the frequency of distribution of all labeled prefrontal boutons in the amygdala based on their size showed that pOFC boutons in IM were consistently the largest among other pOFC and ACC terminals (Fig. $3 H$ ).

Further analysis of the size of boutons using cluster analysis revealed a dual mode of prefrontal terminations in the amygdala, consisting of large (major diameter $\geq 0.95 \mu \mathrm{m}$ ) and small (major diameter $<0.95 \mu \mathrm{m}$ ) boutons (Fig. $4 A$ ). Most pOFC and ACC axons contained both types of terminals or only small boutons, whereas only a few axons $(\sim 8 \%)$ had exclusively large boutons. Interestingly, both large and small boutons from pOFC to IM were, on average, larger than boutons falling into the large and small clusters from pOFC and ACC in other nuclei of the amygdala (Fig. 4A). Stereologic estimation of the relative proportions of large and small boutons in several amygdalar nuclei from pOFC and ACC revealed that only the pOFC pathway to IM consisted of approximately equal numbers of large and small boutons (Fig. 4B). This ratio was significantly elevated compared with the more typical large-to-small bouton ratio in all other examined pathways from pOFC or ACC to the amygdala, which was, on average, $20 \%$ large $/ 80 \%$ small boutons.

We then addressed the issue of the size of boutons from pOFC to IM compared with terminations in the BL nucleus of the amygdala at the synaptic level in the electron microscope $(n=3$; cases BK, BN, and BQ; 142 boutons total; 55 boutons were reconstructed in $3 \mathrm{D})$. A direct comparison of the two pathways from pOFC confirmed that terminals in IM had significantly larger volumes (Fig. $5 A$ ), diameters, and synapses and more mitochondria (not shown) than pOFC boutons that terminated in $\mathrm{BL}$ nucleus (mean bouton volume \pm SEM, $0.46 \pm 0.06 \mu \mathrm{m}^{3}$ in IM; $0.25 \pm 0.02 \mu \mathrm{m}^{3}$ in BL nucleus; mean diameter \pm SEM: $1.10 \pm$ $0.03 \mu \mathrm{m}$ in IM; $0.70 \pm 0.09 \mu \mathrm{m}$ in BL nucleus; $p=0.0001$ ).

We then used double labeling for the pOFC pathway and GAD-67 to identify the postsynaptic sites in IM and the nearby $\mathrm{BL}$ amygdalar nucleus ( $n=2$; cases $\mathrm{BN}$ and $\mathrm{BQ} ; n=87$ boutons). We found that in IM, pOFC boutons innervated both spines and dendrites of inhibitory neurons. The majority (57\%) of pOFC boutons in IM formed asymmetric synapses with spines of GABAergic IM neurons (Fig. 5C,D). The rest of the pOFC boutons $(43 \%)$ formed synapses with GABAergic dendritic shafts.

Using the same double-labeling approach to view pathways and GAD-67, we investigated the synaptic interactions from pOFC axons in the nearby BL nucleus of the amygdala. The BL nucleus is composed of mostly excitatory neurons and a smaller proportion of inhibitory neurons, in proportions similar to the cortex (Pitkänen and Amaral, 1993; Sorvari et al., 1995, 1996a,b; McDonald and Mascagni, 2001). We found that most of the pOFC boutons in BL nucleus formed asymmetric (and presumed excitatory) synapses with spines of excitatory projection neurons (83\%), and the rest of the boutons (17\%) formed asymmetric synapses with inhibitory interneurons (13\% on dendrites and $4 \%$ on spines of local GABAergic neurons; Fig. $5 B, D)$. Additional comparison of the size of boutons from pOFC and ACC $(n=3$ cases, 185 boutons) in BL nucleus and their postsynaptic targets showed that the two pathways had boutons of similar size, which innervated a similar proportion of excitatory projection neurons $(86 \%)$ and local inhibitory interneurons (14\%). These findings at the level of the synapse confirm and extend the findings at the level of the entire system using light microscopy as described above.

Our findings on the quantitative distribution, density, and size of prefrontal terminals in the amygdala indicated that the pOFC to IM pathway was dense and contained more large boutons, which also significantly exceeded in size boutons in other nuclei of the amygdala.

\section{Differential targeting by pOFC pathways of distinct classes of IM neurons}

We then investigated the types of inhibitory neurons targeted by the specialized pOFC pathway in IM. This experiment was based on a recent quantitative study on the composition and relative proportions of distinct inhibitory neurons in the primate IM and their internal circuitry (Zikopoulos et al., 2016). The previous study established that the inhibitory IM neurons are morphologically and neurochemically diverse and are intermingled (Fig. $6 A$ ). Most GABAergic IM neurons coexpress DARPP-32 and are 
A

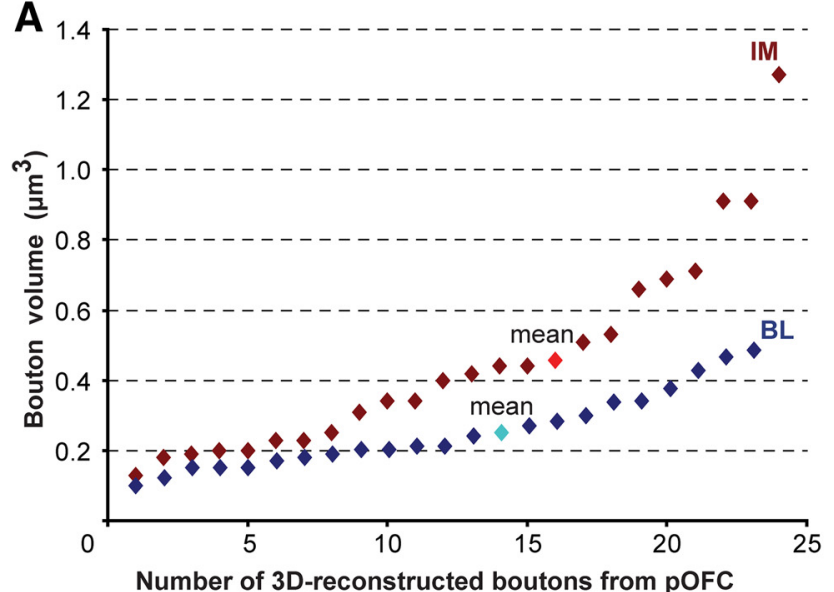

C pOFC synapses on inhibitory IM neurons
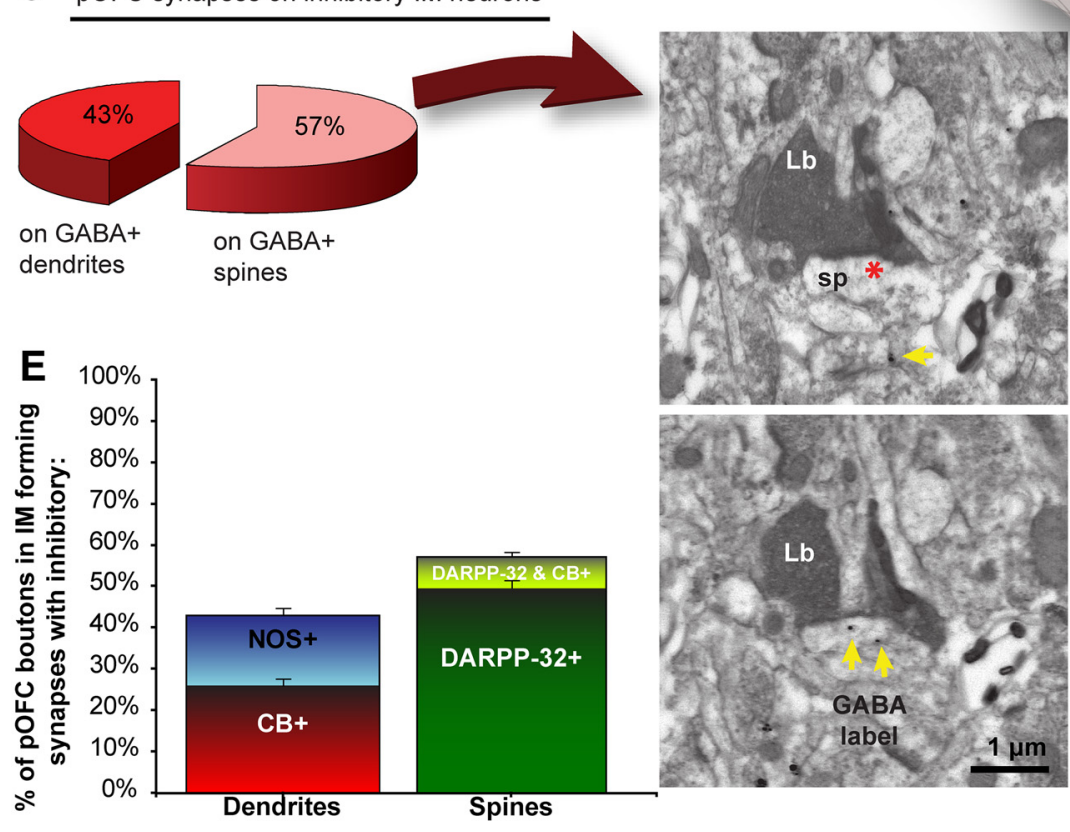

B
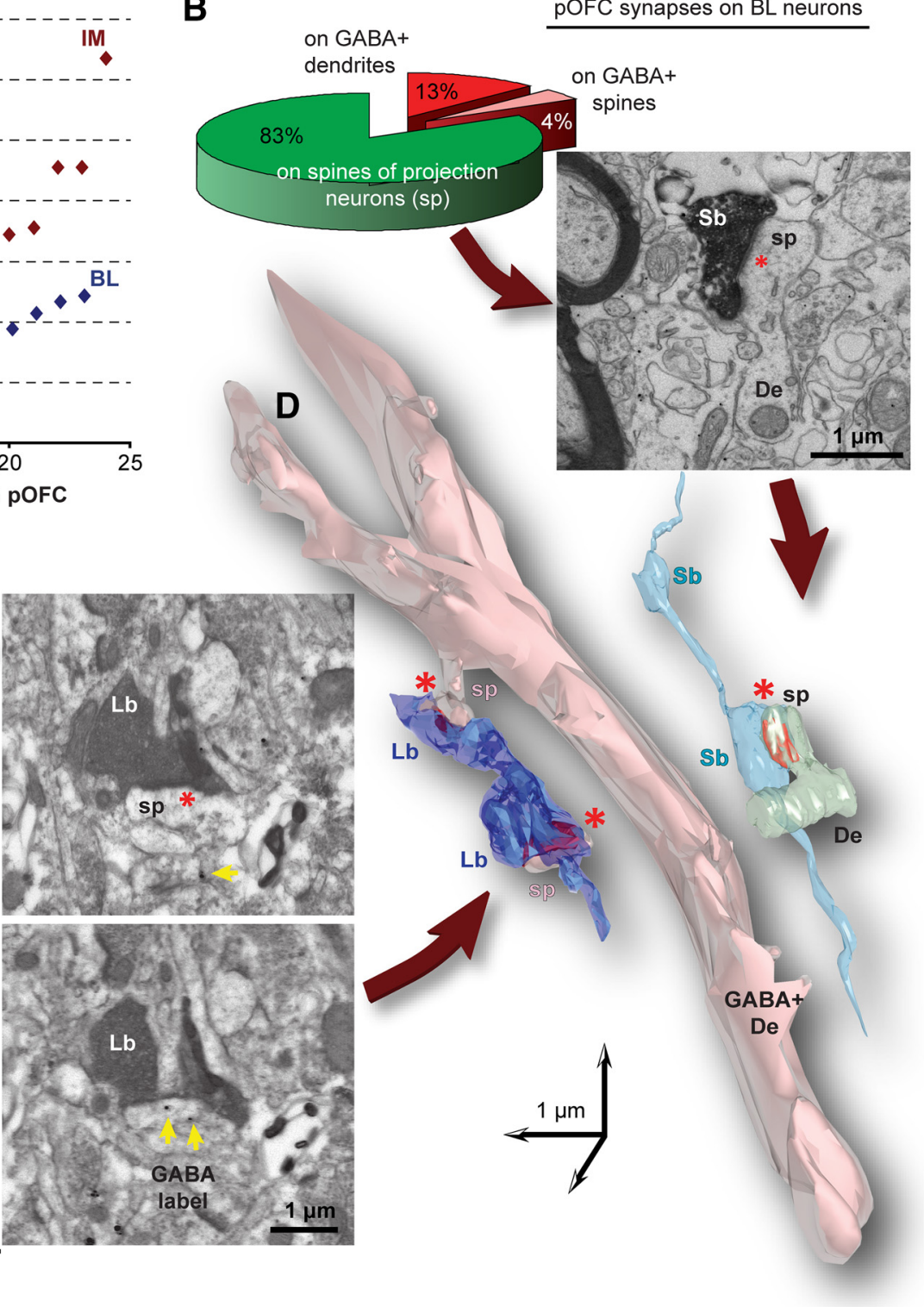

Figure 5. Synaptic and structural features of pOFC terminals in the amygdala. $A$, The size (volume) of labeled boutons from pOFC in IM (brown diamonds) is larger than in the BL nucleus (blue diamonds). $\boldsymbol{B}$, Relatively small p0FC boutons in BL nucleus (Sb) form synapses primarily with spines (sp) of excitatory projection neurons (83\%). The rest form synapses with GABAergic dendrites (De) and spines of local inhibitory interneurons (17\%). The EM photomicrograph shows one ultrathin section from a long series used to follow and reconstruct in 3D a small bouton from pOFC (Sb) and its synapse (red asterisk) with a spine emanating from a dendrite of an excitatory projection neuron in BL nucleus (light blue, Sb; light green, De and sp, postsynaptic processes). C, Relatively large pOFC boutons in IM (Lb) form synapses mainly with spines of DARPP-32+ medium-sized spiny inhibitory neurons (57\%). The rest formed synapses with GABAergic dendrites from aspiny IM inhibitory neurons (43\%). The EM photomicrographs show two adjacent ultrathin sections from a long series used to follow and reconstruct two large boutons from pOFC (Lb) and their synapses (red asterisks) with spines emanating from a dendrite of a medium-sized spiny inhibitory neuron in IM, labeled with GABA (yellow arrows point to gold immunolabeling on the spine and dendrite). $D, 3$ reconstructions of p $0 F C$ boutons and their postsynaptic targets in IM (dark blue, Lb; pink, GABA+De and sp, medium-sized spiny inhibitory neuron processes). The reconstructed dendrites, spines, and boutons are rendered semitransparent to allow visualization of the synapse (red asterisks). $\boldsymbol{E}$, As shown in $\boldsymbol{C}$, most pOFC boutons in IM formed synapses with spines from medium-sized spiny inhibitory neurons that were DARPP-32+ (57\%). The rest formed synapses with dendrites of aspiny CB + (26\%) and NOS + (17\%) inhibitory neurons.

spiny $(\sim 61 \%)$. These neurons have similar morphology to the medium-sized spiny striatal neurons, which are also DARPP$32+$ (Greengard, 2001). Approximately $24 \%$ of the DARPP-32+ (spiny) neurons also coexpress CB. However, there is an additional population of aspiny inhibitory IM neurons that expresses CB, but not DARPP-32 or NOS $(\sim 22 \%)$. The third and smallest class of inhibitory IM neurons are aspiny and are positive for NOS but not CB or DARPP-32 $(\sim 11 \%)$.

We addressed the specific interactions of the pOFC pathway to IM in two ways. First, we examined close appositions of fluorescent-labeled axon terminals and IM neurons using a con- focal laser microscope ( $n=2$; cases BK and BL; $>2000$ appositions per case). We found that $\mathrm{NOS}+, \mathrm{CB}+$, and DARPP-32+ IM neurons were differentially targeted by pOFC axon terminals, as shown in Figure 6, $B$ and $C$. Most pOFC axon terminals were closely apposed to dendritic spines of DARPP-32+ IM neurons $(\sim 60 \%)$, followed by aspiny dendrites of NOS neurons $(\sim 23 \%)$, and aspiny dendrites of $\mathrm{CB}+$ neurons $(\sim 17 \%)$. Approximately $14 \%$ of pOFC boutons were closely apposed to spiny dendrites of DARPP-32+ neurons that also expressed CB.

We then used triple labeling to investigate synapses of pOFC boutons with inhibitory IM neurons labeled with GABA and $\mathrm{CB}$ 

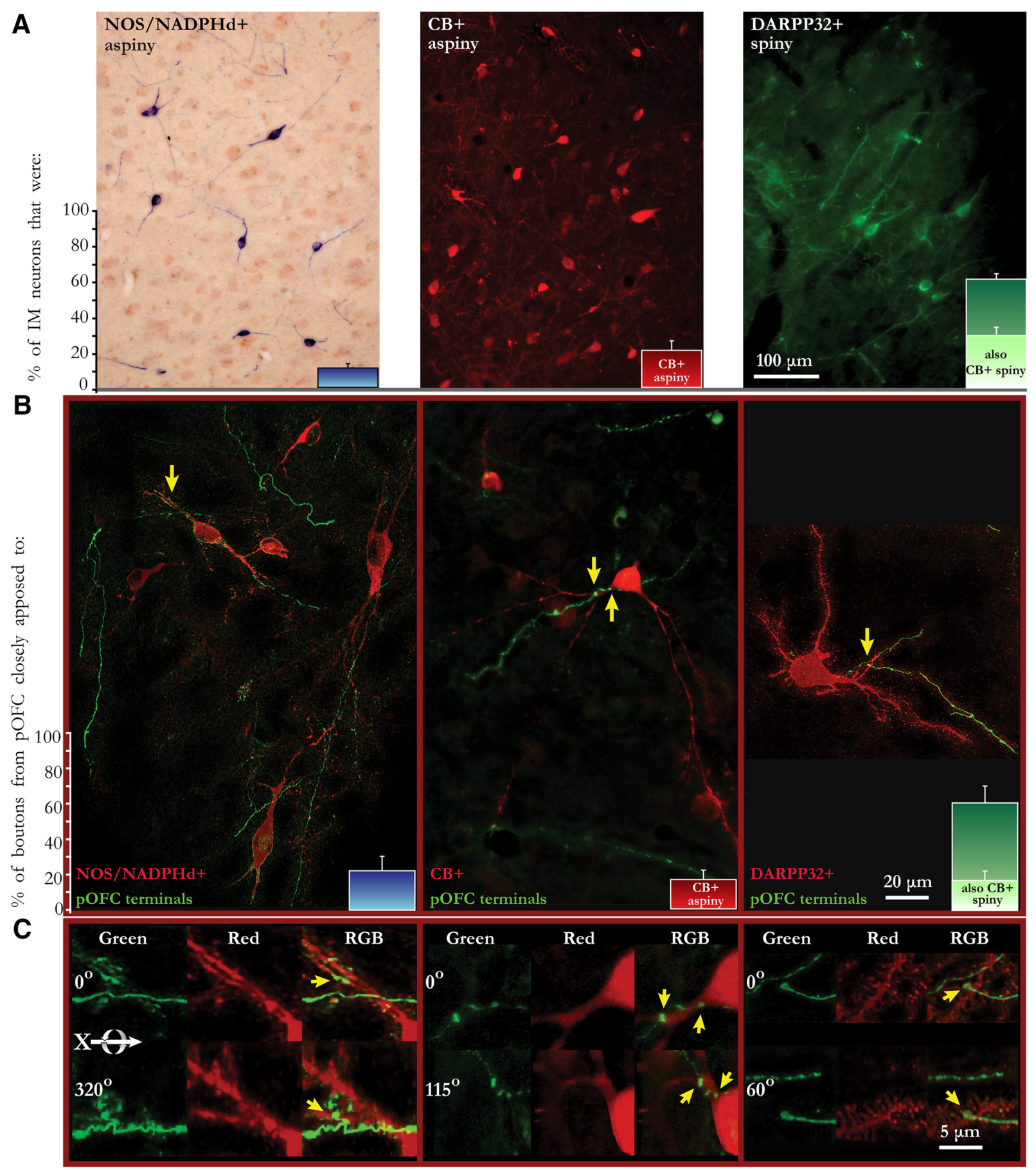

Figure 6. Differential targeting of distinct classes of inhibitory neurons in IM by $\mathrm{pOFC}$. A, Distinct morphological and neurochemical subtypes of inhibitory IM neurons and their relative proportion in the rhesus monkey IM [modified from (Zikopoulos et al., 2016)]. IM neurons are aspiny or spiny. Aspiny IM neurons belong to two classes: those that are NOS/NADPHd + (blue neurons, $\sim 14 \%$ ) and those that are $\mathrm{CB}+$ (red neurons, $\sim 23 \%)$. The majority of neurons in IM are spiny ( $\sim 63 \%)$. All spiny neurons in IM express DARPP-32, and about one-third of them coexpress $C B$ (green neurons). $\boldsymbol{B}$, Examples and relative proportions (bar graphs) of pOFC axon terminations (green fluorescence) closely apposed onto dendrites and spines of neurochemically distinct IM neurons (red fluorescence). Most pOFC terminals were closely apposed to spines of DARPP-32 + IM neurons, followed by appositions with dendrites of aspiny NOS + and (B + IM neurons. C, 3D-projected confocal stacks, rotated on the $x$-axis, show high magnifications of corresponding image segments in $\boldsymbol{B}$ (highlighted by yellow arrows) of closely apposed pOFC terminals (green) onto NOS + (left), $\mathrm{CB}+$ (middle), and DARPP-32+ (right) dendritic segments (red fluorescence). The yellow arrows indicate the same sites of contact in $\boldsymbol{B}$ and $\boldsymbol{C}$.

(Fig. 5E). This strategy made it possible to identify the proportion of pOFC pathways on the unique class of $\mathrm{CB}$ neurons with aspiny dendrites, the proportion of synapses on CB-positive or CB-negative spiny dendrites (which are found on DARPP$32+$ neurons), as well as synapses on nonlabeled dendritic shafts, which correspond to the unique class of NOS + inhibitory neurons.
We used unbiased stereologic methods to sample miniseries of ultrathin sections containing $>100$ labeled pOFC boutons in IM ( $n=2$ cases; 140 boutons) and estimated the number of synapses involving distinct postsynaptic sites. We found that the pOFC pathway formed synapses with double-labeled aspiny dendrites of CB/GABA + IM neurons (26\%), single-labeled aspiny dendrites of GABA+ IM neurons (17\%, presumably emanating 


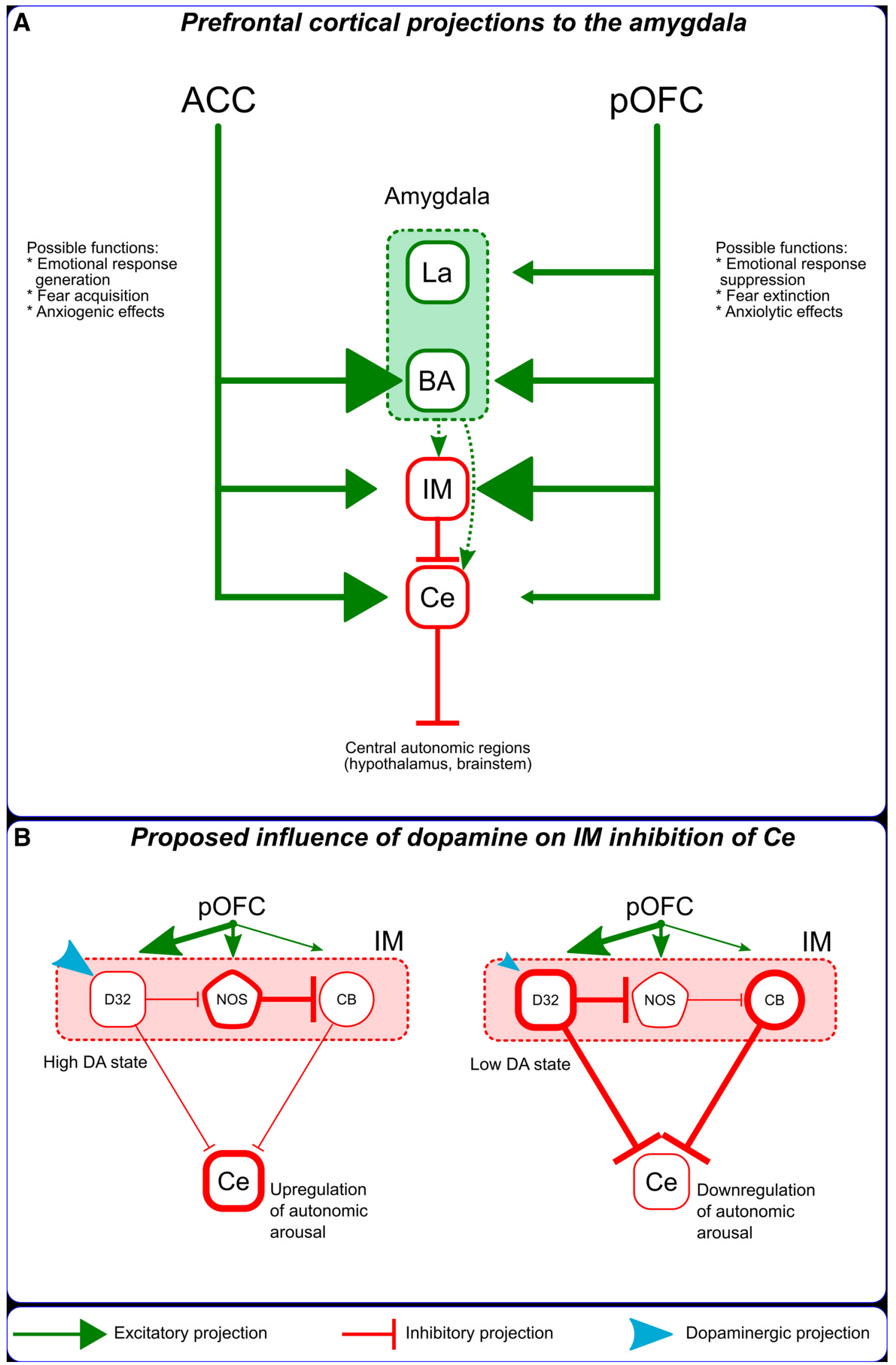

Figure 7. A, Schematic diagram of prefrontal connectivity. Arrowhead sizes reflect relative connection strengths. ACC projections are strongest to the basal nuclei of the amygdala (BA; which includes BL and BM nuclei), followed by (e and then IM. An approximately complementary pattern is shown by pOFC projections: they are strongest in IM, followed by BA, La, and Ce. An excitatory pathway from ACC (area 32) can activate the CeM sector of Ce and thus upregulate autonomic arousal, whereas pOFC is poised to inhibit CeM and therefore downregulate (Figure legend continues.) 
from NOS+ aspiny IM neurons). Another population of terminals formed synapses on double-labeled spines of $\mathrm{CB} / \mathrm{GABA}+$ IM neurons (7\%, presumably emanating from DARPP-32+ and $\mathrm{CB}+$ spiny IM neurons). The rest and largest population of terminals formed synapses on single-labeled spines of GABA+ IM neurons (50\%, which likely emanate from DARPP-32+ spiny neurons). These findings are in line with the general trend from the results obtained using confocal microscopy. Overall, the proportion of large and small labeled boutons from pOFC in IM that targeted spines or dendrites of inhibitory neurons was balanced, $\sim 50 / 50$ (Fig. $5 C, E$ ). Interestingly, spiny and aspiny $\mathrm{CB}+$ inhibitory IM neurons were targeted by a higher proportion of large pOFC terminals, as opposed to aspiny NOS inhibitory IM neurons, which were innervated mainly by small pOFC boutons.

\section{Discussion}

Our findings revealed that the primate pOFC pathway to IM has special features: a high proportion of large terminals, the densest terminations compared with pathways that innervate other amygdalar nuclei, and uneven innervation of distinct classes of inhibitory IM neurons.

The significance of large terminals is based on evidence that they are more likely to activate their targets (Rosenmund and Stevens, 1996; Murthy et al., 1997) and are found in active and stable networks (Thomson, 2000; Zikopoulos and Barbas, 2007a; Becker et al., 2008). The functional import of the inhibitory IM has been studied most extensively in rodents (John et al., 2013). IM neurons project and inhibit the central amygdalar nucleus, whose medial sector (CeM) projects out of the amygdala to autonomic structures. Consequently, the IM in rodents mediates extinction of conditioned fear responses, attributed to activation of infralimbic (IL) cortex, which robustly innervates IM (Likhtik et al., 2008; Amano et al., 2011). Stimulation of IL cortex thus leads to feedforward inhibition of CeM (Likhtik et al., 2008), preventing downstream activation of autonomic structures. The intrinsic amygdalar circuitry is remarkably similar in various species, including mice, rats, gerbils, and cats (Amir et al., 2011).

Based on its dense projections to IM, we suggest that pOFC in primates is equivalent to the rodent IL cortex, which may correspond only to the orbital (basal) part of a large ventromedial region described in humans (Phelps et al., 2004; Zald and Andreotti, 2010; Milad and Quirk, 2012). The shift of IL cortex from a medial position in rodents to a basal (orbital) position in monkeys reflects the prefrontal cortical expansion in evolution. Accordingly, the primate orbitofrontal cortex is large and has more areas than in rodents, but only projections from its most caudal part (pOFC) exquisitely outline the IM in monkeys (Ghashghaei and Barbas, 2002).

Studies in rodents have also identified an area situated above the IL cortex as the prelimbic (PL) cortex, which has distinct connections with the amygdala (Sesack et al., 1989; Vertes, 2004). Unlike the IL cortex, the PL cortex has few terminations in IM but

\section{$\leftarrow$}

(Figure legend continued.) autonomic function. B, Proposed effects of high (large blue arrowhead) and low (small blue arrowhead) dopamine (DA) levels on IM inhibition of Ce. Green arrowhead sizes reflect relative connection strength from pOFC to the three neurochemical classes of inhibitory neurons in IM. High DA levels (large blue arrowhead) have been reported to hyperpolarize IM neurons, whereas low DA levels (small blue arrowhead) do not. In contrast to pOFC pathways, an elevated DA state is consistent with suppression of DARPP32+ and CB + neurons, resulting in disinhibition of Ce activity. Thus, high DA levels (left), which can occur during stressful situations, may counteract or mask a strong pathway from pOFC to IM and reduce inhibitory control on Ce. projects strongly to BL nucleus and CeM (Amano et al., 2011), as found here for ACC area 32. A strong pathway from area 32 to $\mathrm{BL}$ nucleus (which projects to CeM) should activate CeM and facilitate acquisition of fear responses. Based on their common connections, we can thus equate the rodent PL cortex with primate area 32 . The likely opposing functions of the primate pOFC and ACC area 32 can thus be understood by their distinct amygdalar connections, as in rodents. However, the mechanism of engaging or disengaging these areas to mediate opposing functions is unknown, except to note that the physiologic properties of IM neurons depend on context (Paré et al., 2003; Amir et al., 2011).

In light of the present findings, the likely opposite effects by ACC (area 32) and pOFC pathways can be understood in the context of the distinct classes of inhibitory neurons in IM and their intrinsic circuitry, as identified in primates (Zikopoulos et al., 2016). The predominant primate IM class consists of DARPP$32+$ neurons, which we found to be the main target of pOFC axons. A critical feature of IM neurons is their intrinsic circuitry: DARPP-32+ neurons innervate and inhibit NOS+ neurons, which innervate and inhibit the nonspiny $\mathrm{CB}+$ neurons (Zikopoulos et al., 2016). Based on the circuits revealed here, pOFC should activate primarily DARPP-32+ neurons in IM, which would inhibit NOS + neurons and disinhibit $\mathrm{CB}+$ neurons. This circuitry suggests that DARPP-32+ and CB + neurons in IM may have collaborative functions, namely to inhibit $\mathrm{CeM}$ and bar transmission to downstream autonomic structures. By its sheer strength, the pOFC pathway to DARPP-32+ and CB+ IM neurons may represent a prepotent pathway.

How is the opposite state achieved, namely activation of CeM for autonomic arousal? The answer may lie in the diverse functions of the large class of spiny IM neurons when DARPP-32 is phosphorylated at different sites, a process mediated by the level of dopamine in the system (Greengard, 2001; Svenningsson et al., 2004). In mice, dopamine was shown to hyperpolarize amygdalar IM neurons (Marowsky et al., 2005), likely through D1 receptors found on IM neurons (Fuxe et al., 2003; Zikopoulos et al., 2016). The amygdalar DARPP-32+ neurons are akin to spiny striatal neurons (Millhouse, 1986; Kaoru et al., 2010). Based on the intrinsic IM circuitry in primates (Zikopoulos et al., 2016), when DARPP-32+ neurons are hyperpolarized, NOS + neurons would be disinhibited and activated by dopamine through a cascade that involves cGMP and production of the gas transmitter nitric oxide (NO; Sammut et al., 2006; Garthwaite, 2008). In rodents, NO has been implicated in long-term potentiation in the basal amygdala for fear conditioning (Lange et al., 2012). Acquisition of fear responses would favor the PL pathway (primate area 32), which innervates CeM, as well as BL nucleus (which projects to CeM), leading to activation of downstream autonomic structures (Fig. 7). These pathways support the idea that ACC area 32 is part of the "emotional motor system" (Devinsky et al., 1995), along with subgenual area 25 (our personal observations).

The above circuitry helps explain responses to fearful stimuli, consistent with modeling work that predicts cooperative interaction between prefrontal cortex and amygdala for making decisions, such as avoiding danger (John et al., 2016). Prefrontal pathways may help focus on specific negative stimuli by innervating the class of $\mathrm{CB}+$ inhibitory neurons in the amygdalar $\mathrm{BL}$ nucleus and preventing responses to irrelevant stimuli, by analogy with the cortex (Wang et al., 2004; Medalla and Barbas, 2009); this sequence of events would thus limit activation of CeM to specific negative stimuli.

The significance of identifying the analogs of PL and IL cortices across species is also based on their extended involvement 
with, respectively, anxiogenic and anxiolytic effects in rodents (Jinks and McGregor, 1997; Sierra-Mercado et al., 2011; Fuchikami et al., 2015). Can the circuits explain these broader states, which are of high clinical relevance? Consistent evidence across species has correlated high dopamine levels with stress and anxiety, a state that weakens the prefrontal influence (Inglis and Moghaddam, 1999; Rosenkranz and Grace, 2002; Correll et al., 2005; Yokoyama et al., 2005). Hyperpolarization of DARPP-32+ IM neurons may thus occur when dopamine levels are very high, providing a mechanism to help explain how a strong pathway from pOFC to IM can be overridden under high stress.

The specific innervation of inhibitory systems in the amygdala found here, along with the differential impact that dopamine has on them, makes it possible to hypothesize how distinct autonomic states may be achieved. A strong pOFC influence on IM that activates DARPP-32+ and CB + neurons may help modulate autonomic function by downregulating CeM and thereby facilitate social interactions in primates (Kalin et al., 2004; Wellman et al., 2016). In humans, this may be akin to engaging in a neutral or relaxing activity, such as driving along a scenic country road. But when a deer darts across the street, quick vigilance and response ensues by recruiting ACC to activate CeM and downstream autonomic structures. A moderate increase in dopamine would also downregulate IM DARPP-32+ neurons, release their inhibition of NOS + neurons, and produce NO, effectively facilitating pathways to cope with the emergency. In this context, collaboration between orbital and ACC prefrontal areas is likely, as suggested by a recently discovered pathway from area 32 to the middle-deep layers of pOFC (García-Cabezas and Barbas, 2016), which project to the amygdala (Cavada et al., 2000; Ghashghaei et al., 2007) and the thalamic mediodorsal magnocellular (MDmc) nucleus (Xiao et al., 2009). The specific influence of this indirect pathway from area 32 to pOFC on the amygdala is unknown but suggests activation of a tightly knit tripartite and bidirectional system that involves the amygdala, MDmc, and pOFC. This system suggests a mechanism to recruit broad prefrontal areas (Timbie and Barbas, 2014, 2015) for decision and action.

On the other hand, in a panic condition, when survival is perceived to be threatened, dopamine levels markedly increase. DARPP-32+ neurons in IM may thus be primarily inhibited, rendering the pOFC pathway ineffective. At the same time, NOS + neurons are activated and inhibit CB neurons, based on the primate IM circuitry (Zikopoulos et al., 2016). Removal of pOFC control and collapse of two major inhibitory systems in IM would strongly disinhibit CeM. The CeM would also be directly activated by pathways from ACC and BL nucleus, resulting in massive recruitment of autonomic structures and emotional arousal (Fig. 7). This scenario could help explain the state in post-traumatic stress disorder (Bremner et al., 1999), when any loud noise may lead to panic in affected war veterans after return to civilian life.

The primate pOFC and ACC pathways, their innervation of functionally distinct systems in the amygdala, and the intrinsic circuitry within IM (Zikopoulos et al., 2016) thus provide the circuit basis to help explain how distinct autonomic states may be achieved. Influenced in a dynamic way by the level of dopamine in the amygdala, this circuit system engages a switch between a neutral autonomic state and normal reaction to a specific danger for decision and action. In contrast, high dopamine levels render the pOFC pathway ineffective in anxiety states in psychiatric diseases.

\section{References}

Amano T, Duvarci S, Popa D, Paré D (2011) The fear circuit revisited: contributions of the basal amygdala nuclei to conditioned fear. J Neurosci 31:15481-15489. CrossRef Medline

Amir A, Amano T, Pare D (2011) Physiological identification and infralimbic responsiveness of rat intercalated amygdala neurons. J Neurophysiol 105:3054-3066. CrossRef Medline

Barbas H, Medalla M, Alade O, Suski J, Zikopoulos B, Lera P (2005) Relationship of prefrontal connections to inhibitory systems in superior temporal areas in the rhesus monkey. Cereb Cortex 15:1356-1370. Medline

Becker N, Wierenga CJ, Fonseca R, Bonhoeffer T, Nägerl UV (2008) LTD induction causes morphological changes of presynaptic boutons and reduces their contacts with spines. Neuron 60:590-597. CrossRef Medline

Bremner JD, Staib LH, Kaloupek D, Southwick SM, Soufer R, Charney DS (1999) Neural correlates of exposure to traumatic pictures and sound in Vietnam combat veterans with and without posttraumatic stress disorder: a positron emission tomography study. Biol Psychiatry 45:806-816. CrossRef Medline

Bunce JG, Barbas H (2011) Prefrontal pathways target excitatory and inhibitory systems in memory-related medial temporal cortices. Neuroimage 55:1461-1474. CrossRef Medline

Bunce JG, Zikopoulos B, Feinberg M, Barbas H (2013) Parallel prefrontal pathways reach distinct excitatory and inhibitory systems in memoryrelated rhinal cortices. J Comp Neurol 512:4260-4283. CrossRef Medline

Cavada C, Compañy T, Tejedor J, Cruz-Rizzolo RJ, Reinoso-Suárez F (2000) The anatomical connections of the macaque monkey orbitofrontal cortex. A review. Cereb Cortex 10:220-242. CrossRef Medline

Correll CM, Rosenkranz JA, Grace AA (2005) Chronic cold stress alters prefrontal cortical modulation of amygdala neuronal activity in rats. Biol Psychiatry 58:382-391. CrossRef Medline

De Olmos J (1990) Amygdaloid nuclear gray complex. In: The human nervous system (Paxinos G, ed), pp 583-710. San Diego: Academic.

Devinsky O, Morrell MJ, Vogt BA (1995) Contributions of anterior cingulate cortex to behaviour. Brain 118:279-306. CrossRef Medline

Dombrowski SM, Barbas H (1996) Differential expression of NADPH diaphorase in functionally distinct prefrontal cortices in the rhesus monkey. Neuroscience 72:49-62. CrossRef Medline

Fiala JC (2005) Reconstruct: a free editor for serial section microscopy. J Microsc 218:52-61. CrossRef Medline

Fuchikami M, Thomas A, Liu R, Wohleb ES, Land BB, DiLeone RJ, Aghajanian GK, Duman RS (2015) Optogenetic stimulation of infralimbic PFC reproduces ketamine's rapid and sustained antidepressant actions. Proc Natl Acad Sci U S A 112:8106-8111. CrossRef Medline

Fuxe K, Jacobsen KX, Höistad M, Tinner B, Jansson A, Staines WA, Agnati LF (2003) The dopamine D1 receptor-rich main and paracapsular intercalated nerve cell groups of the rat amygdala: relationship to the dopamine innervation. Neuroscience 119:733-746. CrossRef Medline

García-Cabezas MÁ, Barbas H (2014) A direct anterior cingulate pathway to the primate primary olfactory cortex may control attention to olfaction. Brain Struct Funct 219:1735-1754. CrossRef Medline

García-Cabezas MA, Barbas H (2016) Anterior cingulate pathways may affect emotions through orbitofrontal cortex. Cereb Cortex. Advance online publication, September 20, 2016. CrossRef Medline

Garthwaite J (2008) Concepts of neural nitric oxide-mediated transmission. Eur J Neurosci 27:2783-2802. CrossRef Medline

Germuska M, Saha S, Fiala J, Barbas H (2006) Synaptic distinction of laminar specific prefrontal-temporal pathways in primates. Cereb Cortex 16: 865-875. Medline

Ghashghaei HT, Barbas H (2002) Pathways for emotion: Interactions of prefrontal and anterior temporal pathways in the amygdala of the rhesus monkey. Neuroscience 115:1261-1279. CrossRef Medline

Ghashghaei HT, Hilgetag CC, Barbas H (2007) Sequence of information processing for emotions based on the anatomic dialogue between prefrontal cortex and amygdala. Neuroimage 34:905-923. CrossRef Medline

Greengard P (2001) The neurobiology of slow synaptic transmission. Science 294:1024-1030. CrossRef Medline

Gundersen HJ (1986) Stereology of arbitrary particles. A review of unbiased number and size estimators and the presentation of some new ones, in memory of William R. Thompson. J Microsc 143:3-45. Medline

Howard CV, Reed MG (1998) Unbiased stereology, three-dimensional measurement in microscopy. Oxford: BIOS Scientific.

Inglis FM, Moghaddam B (1999) Dopaminergic innervation of the 
amygdala is highly responsive to stress. J Neurochem 72:1088-1094. Medline

Jinks AL, McGregor IS (1997) Modulation of anxiety-related behaviours following lesions of the prelimbic or infralimbic cortex in the rat. Brain Res 772:181-190. CrossRef Medline

John YJ, Bullock D, Zikopoulos B, Barbas H (2013) Anatomy and computational modeling of networks underlying cognitive-emotional interaction. Front Hum Neurosci 7:101. Medline

John YJ, Zikopoulos B, Bullock D, Barbas H (2016) The emotional gatekeeper: a computational model of attentional selection and supression through the pathway from the amygdala to the thalamic reticular nucleus. PLoS Comput Biol 12:e1004722. CrossRef Medline

Johnston JB (1923) Further contributions to the study of the evolution of the forebrain. J Comp Neurol 35:337-481. CrossRef

Kalin NH, Shelton SE, Davidson RJ (2004) The role of the central nucleus of the amygdala in mediating fear and anxiety in the primate. J Neurosci 24:5506-5515. CrossRef Medline

Kaoru T, Liu FC, Ishida M, Oishi T, Hayashi M, Kitagawa M, Shimoda K, Takahashi H (2010) Molecular characterization of the intercalated cell masses of the amygdala: implications for the relationship with the striatum. Neuroscience 166:220-230. CrossRef Medline

Lange MD, Doengi M, Lesting J, Pape HC, JünglingK (2012) Heterosynaptic long-term potentiation at interneuron-principal neuron synapses in the amygdala requires nitric oxide signalling. J Physiol 590:131-143. CrossRef Medline

Likhtik E, Popa D, Apergis-Schoute J, Fidacaro GA, Paré D (2008) Amygdala intercalated neurons are required for expression of fear extinction. Nature 454:642-645. CrossRef Medline

Marowsky A, Yanagawa Y, Obata K, Vogt KE (2005) A specialized subclass of interneurons mediates dopaminergic facilitation of amygdala function. Neuron 48:1025-1037. CrossRef Medline

McDonald AJ, Mascagni F (2001) Colocalization of calcium-binding proteins and GABA in neurons of the rat basolateral amygdala. Neuroscience 105:681-693. CrossRef Medline

Medalla M, Barbas H (2009) Synapses with inhibitory neurons differentiate anterior cingulate from dorsolateral prefrontal pathways associated with cognitive control. Neuron 61:609-620. CrossRef Medline

Medalla M, Barbas H (2010) Anterior cingulate synapses in prefrontal areas 10 and 46 suggest differential influence in cognitive control. J Neurosci 30:16068-16081. CrossRef Medline

Medalla M, Barbas H (2012) The anterior cingulate cortex may enhance inhibition of lateral prefrontal cortex via $\mathrm{m} 2$ cholinergic receptors at dual synaptic sites. J Neurosci 32:15611-15625. CrossRef Medline

Milad MR, Quirk GJ (2012) Fear extinction as a model for translational neuroscience: ten years of progress. Annu Rev Psychol 63:129-151. CrossRef Medline

Millhouse OE (1986) The intercalated cells of the amygdala. J Comp Neurol 247:246-271. CrossRef Medline

Morrison SE, Salzman CD (2011) Representations of appetitive and aversive information in the primate orbitofrontal cortex. Ann N Y Acad Sci 1239:59-70. CrossRef Medline

Murthy VN, Sejnowski TJ, Stevens CF (1997) Heterogeneous release properties of visualized individual hippocampal synapses. Neuron 18:599612. CrossRef Medline

Palomares-Castillo E, Hernández-Pérez OR, Pérez-Carrera D, CrespoRamírez M, Fuxe K, Pérez de la Mora M (2012) The intercalated paracapsular islands as a module for integration of signals regulating anxiety in the amygdala. Brain Res 1476:211-234. CrossRef Medline

Paré D, Royer S, Smith Y, Lang EJ (2003) Contextual inhibitory gating of impulse traffic in the intra-amygdaloid network. Ann N Y Acad Sci 985: 78-91. Medline

Pessoa L (2010) Emotion and cognition and the amygdala: from "what is it?" to "what's to be done?". Neuropsychologia 48:3416-3429. CrossRef Medline

Peters A, Palay SL, Webster HD (1991) The fine structure of the nervous system. Neurons and their supporting cells, Ed 3. New York: Oxford UP.

Phelps EA, Delgado MR, Nearing KI, LeDoux JE (2004) Extinction learning in humans: role of the amygdala and vmPFC. Neuron 43:897-905. CrossRef Medline

Pierce JP, Lewin GR (1994) An ultrastructural size principle. Neuroscience 58:441-446. CrossRef Medline

Pierce JP, Mendell LM (1993) Quantitative ultrastructure of Ia boutons in the ventral horn: scaling and positional relationships. J Neurosci 13: 4748-4763. Medline

Pitkänen A, Amaral DG (1993) Distribution of calbindin-D28k immunoreactivity in the monkey temporal lobe: the amygdaloid complex. J Comp Neurol 331:199-224. CrossRef Medline

Price JL, Amaral DG (1981) An autoradiographic study of the projections of the central nucleus of the monkey amygdala. J Neurosci 1:1242-1259. Medline

Price JL, Russchen FT, Amaral DG (1987) The limbic region. II. The amygdaloid complex. In: Handbook of chemical neuroanatomy, Vol 5, integrated systems of the CNS, part I (Björklund A, Hökfelt T, Swanson LW, eds), pp 279-381. Amsterdam: Elsevier.

Reiner A, Veenman CL, Medina L, Jiao Y, Del Mar N, Honig MG (2000) Pathway tracing using biotinylated dextran amines. J Neurosci Methods 103:23-37. CrossRef Medline

Richmond FJ, Gladdy R, Creasy JL, Kitamura S, Smits E, Thomson DB (1994) Efficacy of seven retrograde tracers, compared in multiplelabelling studies of feline motoneurones. J Neurosci Methods 53:35-46. CrossRef Medline

Rosenkranz JA, Grace AA (2002) Cellular mechanisms of infralimbic and prelimbic prefrontal cortical inhibition and dopaminergic modulation of basolateral amygdala neurons in vivo. J Neurosci 22:324-337. Medline

Rosenmund C, Stevens CF (1996) Definition of the readily releasable pool of vesicles at hippocampal synapses. Neuron 16:1197-1207. CrossRef Medline

Rudebeck PH, Saunders RC, Prescott AT, Chau LS, Murray EA (2013) Prefrontal mechanisms of behavioral flexibility, emotion regulation and value updating. Nat Neurosci 16:1140-1145. CrossRef Medline

Salzman CD, Fusi S (2010) Emotion, cognition, and mental state representation in amygdala and prefrontal cortex. Annu Rev Neurosci 33:173-202. CrossRef

Salzman CD, Paton JJ, Belova MA, Morrison SE (2007) Flexible neural representations of value in the primate brain. Ann N Y Acad Sci 1121:336354. CrossRef

Sammut S, Dec A, Mitchell D, Linardakis J, Ortiguela M, West AR (2006) Phasic dopaminergic transmission increases $\mathrm{NO}$ efflux in the rat dorsal striatum via a neuronal NOS and a dopamine $\mathrm{D}(1 / 5)$ receptor-dependent mechanism. Neuropsychopharmacology 31:493-505. CrossRef Medline

Sesack SR, Deutch AY, Roth RH, Bunney BS (1989) Topographical organization of the efferent projections of the medial prefrontal cortex in the rat: an anterograde tract-tracing study with Phaseolus vulgaris leucoagglutinin. J Comp Neurol 290:213-242. CrossRef Medline

Shepherd GM, Harris KM (1998) Three-dimensional structure and composition of $\mathrm{CA} 3 \rightarrow \mathrm{CA} 1$ axons in rat hippocampal slices: implications for presynaptic connectivity and compartmentalization. J Neurosci 18:83008310. Medline

Sierra-Mercado D, Padilla-Coreano N, Quirk GJ (2011) Dissociable roles of prelimbic and infralimbic cortices, ventral hippocampus, and basolateral amygdala in the expression and extinction of conditioned fear. Neuropsychopharmacology 36:529-538. CrossRef Medline

Sorvari H, Soininen H, Paljärvi L, Karkola K, PitkänenA (1995) Distribution of parvalbumin-immunoreactive cells and fibers in the human amygdaloid complex. J Comp Neurol 360:185-212. CrossRef Medline

Sorvari H, Soininen H, PitkänenA (1996a) Calretinin-immunoreactive cells and fibers in the human amygdaloid complex. J Comp Neurol 369:188 208. CrossRef Medline

Sorvari H, Soininen H, PitkänenA (1996b) Calbindin-D28K-immunoreactive cells and fibres in the human amygdaloid complex. Neuroscience 75:421-443. CrossRef Medline

Stefanacci L, Amaral DG (2002) Some observations on cortical inputs to the macaque monkey amygdala: an anterograde tracing study. J Comp Neurol 451:301-323. CrossRef Medline

Svenningsson P, Nishi A, Fisone G, Girault JA, Nairn AC, Greengard P (2004) DARPP-32: an integrator of neurotransmission. Annu Rev Pharmacol Toxicol 44:269-296. CrossRef Medline

Thomson AM (2000) Molecular frequency filters at central synapses. Prog Neurobiol 62:159-196. Medline

Timbie C, Barbas H (2014) Specialized pathways from the primate amygdala to posterior orbitofrontal cortex. J Neurosci 34:8106-8118. CrossRef Medline

Timbie C, Barbas H (2015) Pathways for emotions: specializations in the 
amygdalar, mediodorsal thalamic, and posterior orbitofrontal network. J Neurosci 35:11976-11987. CrossRef Medline

Veenman CL, Reiner A, Honig MG (1992) Biotinylated dextran amine as an anterograde tracer for single- and double-labeling studies. J Neurosci Methods 41:239-254. CrossRef Medline

Vertes RP (2004) Differential projections of the infralimbic and prelimbic cortex in the rat. Synapse 51:32-58. CrossRef Medline

Wang XJ, Tegnér J, Constantinidis C, Goldman-Rakic PS (2004) Division of labor among distinct subtypes of inhibitory neurons in a cortical microcircuit of working memory. Proc Natl Acad Sci U S A 101:1368-1373. CrossRef Medline

Wellman LL, Forcelli PA, Aguilar BL, Malkova L (2016) Bidirectional control of social behavior by activity within basolateral and central amygdala of primates. J Neurosci 36:8746-8756. CrossRef Medline

West MJ, Slomianka L, Gundersen HJ (1991) Unbiased stereological estimation of the total number of neurons in the subdivisions of the rat hippocampus using the optical fractionator. Anat Rec 231:482-497. CrossRef Medline

Xiao D, Zikopoulos B, Barbas H (2009) Laminar and modular organization of prefrontal projections to multiple thalamic nuclei. Neuroscience 161: 1067-1081. CrossRef Medline
Yokoyama M, Suzuki E, Sato T, Maruta S, Watanabe S, Miyaoka H (2005) Amygdalic levels of dopamine and serotonin rise upon exposure to conditioned fear stress without elevation of glutamate. Neurosci Lett 379:3741. CrossRef Medline

Zald DH, Andreotti C (2010) Neuropsychological assessment of the orbital and ventromedial prefrontal cortex. Neuropsychologia 48:3377-3391. CrossRef Medline

Zikopoulos B, Barbas H (2006) Prefrontal projections to the thalamic reticular nucleus form a unique circuit for attentional mechanisms. J Neurosci 26:7348-7361. CrossRef Medline

Zikopoulos B, Barbas H (2007a) Circuits for multisensory integration and attentional modulation through the prefrontal cortex and the thalamic reticular nucleus in primates. Rev Neurosci 18 417-438.

Zikopoulos B, Barbas H (2007b) Parallel driving and modulatory pathways link the prefrontal cortex and thalamus PLoS One 2:e848. CrossRef

Zikopoulos B, Barbas H (2012) Pathways for emotions and attention converge on the thalamic reticular nucleus in primates. J Neurosci 32:5338 5350. CrossRef Medline

Zikopoulos B, John YJ, García-Cabezas MÁ, Bunce JG, Barbas H (2016) The intercalated nuclear complex of the primate amygdala. Neuroscience 330: 267-290. CrossRef Medline 